\title{
Computer-aided design of multi-purpose steel headframes for mines with a new technical level
}

\author{
Elena Kassikhina $^{1 *}$, Vladimir Pershin ${ }^{1}$, and Nina Rusakova ${ }^{2}$ \\ ${ }^{1}$ T.F. Gorbachev Kuzbass State Technical University, 650000, 28 Vesennaya Str., Kemerovo, Russia \\ ${ }^{2}$ Kemerovo State University, 650000, 6 Krasnaya Str., Kemerovo, Russia
}

\begin{abstract}
The existing structures of the steel sinking headgear and permanent headframe do not meet the requirements of resource saving (metal consumption and manpower input at installation), and the present methods of the headframe designing do not fully reflect recent possibilities of applying of the advanced information technologies. Technical level of the modern software makes it possible for designers to set up multiple numerical experiments to create a computer simulation that allows solving the problem without field and laboratory experiments, and therefore without special costs. In this regard, a mathematical simulation has been developed and based on it, software to select cross-sections of multipurpose steel headframe elements and to calculate proper weight of its metal structures depending on the characteristics and hoisting equipment. A headframe drawing is displayed, as the results of the software work, including list of elements, obtained optimal hoisting equipment in accordance with the initial data. The software allows speeding up graphic work and reducing manpower input on calculations and paper work. The software allows developing a three-dimensional image of the structure and its functional blocks, based on the obtained initial parameters, as well as developing control software for units with numerical control (NC) in order to manufacture multi-purpose headframes.
\end{abstract}

\section{Introduction}

The existing constructive solutions of the steel sinking headgear and permanent headframe in a form of multi-element lattice structures do not meet the requirements of resource saving due to the great complexity of manufacturing and installation [1-9]. The presence of a large number of individual units and sections of elements does not allow to fully minimizing their design cost by means of advanced information technologies.

\section{Object of research}

The design of a multi-purpose steel headframe was developed at the US\&MC (Department of Underground Structures and Mines Construction), KuzSTU (Fig. 1), consisting of permanent blocks 1 and 2 and interchangeable functional blocks 3, 4 and 5 used both for carrying out headwork and works necessary during operation mode.

\footnotetext{
*Correspondent author: kalena-07@mail.ru
} 


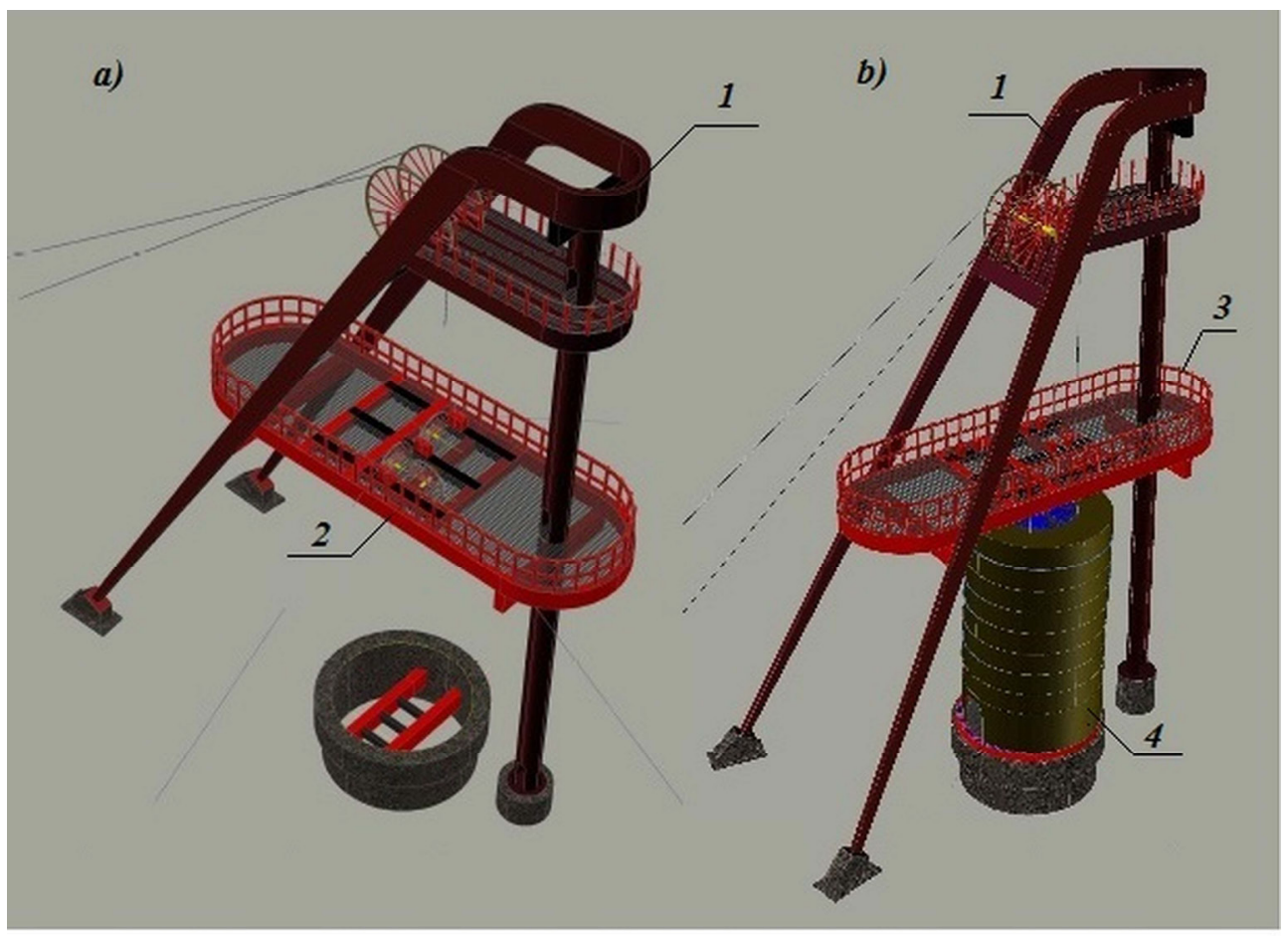

Fig. 1. Multi-purpose steel headframe: a) - scheme for headwork; b) - scheme for operation mode; 1 - pulley; 2 - sinking sheave wheels pad; 3 - shock absorber pad ; 4 - rig.

\section{Aim of research}

Create a multi-purpose headframe calculation model (MPH) in the AutoCAD software environment in order to display, analyze and document the calculation results.

\section{Results}

The proposed idea of independently working structural blocks significantly reduces a number of the controlled variables that a designer can vary while designing a headframe. This greatly simplifies automation of the design process in search of an optimal solution, herewith not a typical, but individual one.

This approach allows forming a certain computational space of the design variables for a headframe - a set of the output parameters in each specific case $A=\left\{\begin{array}{lll}a_{1}, \ldots & a_{n}\end{array}\right\}$, from which its topology and dimensions of the cross-sections of the elements depend on.

The output parameters include, in particular, a headframe height $H_{h f}$, jib angle $\alpha_{R}$, diameter $d_{h f}$, weight $q_{h f}$ and rupture stress $\mathrm{S}_{r u p}$ of a wire-rope, pulley diameter $D_{p l l}$, diameter $D_{d r}$ and width $B_{d r}$ of a hoisting drum, static balanced wire-rope $S_{\text {static }}$, fleeting angles of wire-rope string to horizon $\beta_{i}^{\min }$ и $\beta_{i}{ }^{\max }$ (minimum and maximum of allowable values), length $L_{\text {string }}$ and deviation angles $\alpha_{d e v}$ of a wire-rope string, rig height $H_{\text {rig }}$, rig diameter $D_{\text {rig }}$, cross-section dimensions of elements $h_{w i}, h_{f i}, b_{w i}, b_{f i}$. Values of the listed output parameters depend on various characteristics $a_{i}=f_{i}\left(x_{1}, \ldots \ldots x_{k}\right)$. 
As a result of the research, the main characteristics were acknowledged $a_{i}$, influencing the formation of optimal design parameters $A$.

Characteristics defining the output parameters of a headframe are divided into three groups as follows:

- technological characteristics in the 'mine shaft' subsystem: shaft diameter in the light $D_{\text {shaft, }}$ mine mouth thickness $t_{m m}$, shaft depth $H$, step of shaft reinforcement tiers consider as $3 \mathrm{~m}$, length of shipment-sized set of cable guide $L_{\text {length. }}$.

- technological characteristics in the 'safety devices' subsystem: length of wire-rope to hoist long gauge $l_{\text {hoist }}=3 \mathrm{~m}$; height of over-travel of conveyance or a load $h_{3}=6 \mathrm{~m}$, length of straight section of the shock-absorbing wire-rope $l_{a b s}=3 \mathrm{~m}$, section of the rig closed area to inspect couplings of shock-absorbing wire-ropes $l_{\text {coup }}=2 \mathrm{~m}$; marking of a sinling sheave wheels platform according to the technological requirements $h_{a b s}-$ minimum value $h_{\text {abs }}^{\text {min }}=L_{\text {eng }}+t_{\text {hoist }}+l_{\text {coup }}+2 \mathrm{~m}$.

- technological characteristics in the 'hoist' subsystem: location of hoist relative to shaft $\boldsymbol{l}$ (distance) and $\boldsymbol{c}$ (drum excess), conveyances (type, height $h_{c o n}$, width $b_{c o n}$, length $a_{c o n}$, suspended load $Q_{\kappa}$, distance between hoisting wire-ropes $b$, number of wire-ropes $n$, mark of unloading area $h_{1}$ ); branches of hoisting wire-rope (marking steel grade $\sigma_{\mathrm{B}}$ and wire-rope GOST).

Note that some characteristics are constants and are defined by a customer. Other characteristics are determined in the process of numerical calculations.

Mathematical model to search optimal parameters is presented by the equations herein below.

One of the defining calculated parameters $\boldsymbol{a}_{1}$ is the value and direction of rope rupture stress $\tilde{S}_{\text {rup }}=f\left(d_{\text {rope }}, q_{\text {rope }}, \angle \beta\right)$.

Wire-rope diameter $d_{\text {rope }} \geq d_{\min }$ and its specific weight $q_{\text {rope }} \geq q_{\min }$, accepted from the rope database under the verification condition $[m] \leq m$

$$
\begin{gathered}
d_{\text {ropemin }}=\sqrt{\frac{Q_{\kappa}}{\frac{\sigma_{B} \bar{Q}_{c}}{[m] g}-\bar{q}\left(l_{\text {rope }}\right) \cdot 10^{-6}}} \\
q_{\text {rope } \min }=\frac{Q_{\kappa}}{\frac{\sigma_{B} \cdot 10^{6}}{[m] \gamma^{*} g}-\left(l_{\text {rope }}\right)},
\end{gathered}
$$

where $l_{\text {rope }}=H+h_{1}+h_{a b s}+l_{\text {abs }}+0.75\left(0,5 D_{\text {pll }}\right)$ - estimated rope length; $[\mathrm{m}]-$ permissible factor of safety for rope; $m, n, \bar{Q}_{c}, \gamma^{*}, \bar{q}$ - parameters that depend on wire-rope structure.

Calculated parameter $a_{2}-D_{p l l} \geq 79 d_{\text {rope }}$ is selected from a base of sheave wheels, then drum diameter is selected in the same way $D_{d r} \geq 79 d_{\text {rope }}$, and corresponding values of drum width $B$ of hoist and static rope tension $S_{\text {static. }}$.

$$
\begin{gathered}
B \geq B_{d r}^{\min }=\left[\frac{l_{\text {rope }}+l_{\text {reserv }}}{\pi D_{d r}}+n_{w}\right] \cdot\left(d_{\text {rope }}+S_{w}\right) \\
S_{\text {staric }} \geq S_{\text {static }}^{\text {min }}=\left(\boldsymbol{Q}_{k}+\boldsymbol{q} \cdot n \cdot\left(l_{\text {rope }}\right) \cdot \boldsymbol{g},\right.
\end{gathered}
$$

where $l_{\text {reserv }}, n_{w}, S_{w}, c$ - the constants that depend on the hoist type. 
Parameters $a_{3}-H_{h f}$ (depend on location of hoist relative to shaft $l$ and related restrictions, as well as location of the unloading $h_{1}$ and sinking areas $h_{\text {abs}}$ ).

Restrictions [5]:

Fleeting angles of wire-rope string to horizon $30^{\circ} \leq \beta=\operatorname{arcctg} \frac{l-0,5 D_{p l l}}{l_{\text {rope }}-H-c} \leq 50^{\circ}$

Angle of deviation $\alpha_{d e v} \leq 1^{\circ} 30^{\prime}$

Length of wire-rope string

$$
\begin{aligned}
& \alpha_{d e v}^{d}=\operatorname{arctg} \frac{2 \boldsymbol{B}+\boldsymbol{B}_{R}-\boldsymbol{b}-2 \cdot 6 \cdot\left(\boldsymbol{d}_{\mathrm{rope}}+\boldsymbol{S}_{w}\right)}{2 \boldsymbol{L}_{\text {string } \alpha}} \\
& \alpha_{d e v}^{h}=\operatorname{arctg} \frac{\boldsymbol{b}-\boldsymbol{B}_{R}-2 \cdot\left(\boldsymbol{B}-\boldsymbol{B}_{d r}^{\min }\right)}{2 \boldsymbol{L}_{\text {string } \alpha}}
\end{aligned}
$$

$$
\begin{aligned}
& L_{\text {string }}=\sqrt{\left(l_{\text {rope }}-H-c\right)^{2}+\left(l-\frac{D_{p l l}}{2}\right)^{2}} \leq 65 \mathbf{m} \\
& \boldsymbol{L}_{\text {string } \alpha}^{\min 1}=\frac{2 \boldsymbol{B}+\boldsymbol{B}_{\mathrm{p}}-\boldsymbol{b}-2 \cdot 6 \cdot\left(\boldsymbol{d}_{\text {rope }}+\boldsymbol{S}_{w}\right)}{2 \operatorname{tg} 1,5^{\circ}} \\
& \boldsymbol{L}_{\text {sting } \alpha}^{\min 2}=\frac{\boldsymbol{b}-\boldsymbol{B}_{R}-2 \cdot\left(\boldsymbol{B}-\boldsymbol{B}_{d r}^{\min }\right)}{2 \operatorname{tg} 1,5^{\circ}}
\end{aligned}
$$

Considering that $\left(l-0,5 D_{\text {шк }}\right)<L_{\text {string }}{ }^{\min } \leq 65 \mathrm{~m}$

Therefore the area of permissible values for headframe height $H_{h f}$

$$
\begin{aligned}
& H_{\beta i}^{\min }=\left(l_{\text {rope }}-H\right)_{\beta^{\min }}=\left(l-0,5 D_{p l l}\right) \cdot \operatorname{tg} 30^{\circ}+c \\
& H_{\beta i}^{\text {max }}=\left(l_{\text {rope }}-H\right)_{\beta^{\max }}=\left(l-0,5 D_{p l l}\right) \cdot \operatorname{tg} 50^{0}+c \\
& H_{L}^{\max }=\left(l_{\text {rope }}-H\right)_{L}=\sqrt{65^{2}-\left(l-\frac{D_{p l l}}{2}\right)^{2}}+c \\
& H_{\alpha i}^{\text {min }}=\left(l_{\text {rope }}-H\right)_{\alpha}=\sqrt{\left(L_{\text {string } \alpha}^{\min }\right)^{2}-\left(l-\frac{D_{p l l}}{2}\right)^{2}}+c
\end{aligned}
$$

The obtained values $H_{h f}\left(H_{\alpha i}{ }^{\min }, H_{\beta i}{ }^{\min }, H_{\beta i}{ }^{\max }, H_{L}{ }^{\max }\right)$ are calculated as dependencies on the distance $l$, set by a customer, which, in turn, has boundary conditions [3]:

condition for the maximum possible convergence of hoist foundation and jib foundation according to the Yuzhgiproshakhta formula:

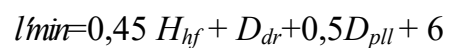

condition for the maximum possible convergence of hoist and headframe to avoid vibration from headframe to hoist:

$$
l^{\prime \prime m i n}=0,6 H_{h f}+{ }_{D d r}+3,5 \mathrm{~m}
$$

condition for the maximum possible distance of hoist from headframe that guarantees absence of vibration in the inclined part of hoisting rope without instalation of additional supporting pulleys:

$$
\text { lmax }=1.4\left(H_{h f}-c\right)+0.5 D_{\text {pll }}
$$

Taking these conditions into account, the boundary conditions for $H_{h f}\left(H l^{\prime}\right.$ min, $H l^{\prime \prime} m i n$, $H$ Hmax) are calculated as per the factor $l$.

You should also consider the boundary conditions for $H_{h f}$ as per the technological requirements: 


$$
H_{h f t} \geq h_{a b s}+3 \mathrm{~m}
$$

To perform numerical calculations and visualize the results, a software package was developed "Program to Select Cross-Sections of the Elements for Multi-Purpose Steel Headframe and to Calculate Own Weight of the Headframe Steel Structures" (certificate \# 2019663146) with the following functionality:

- initial data loading:

- user's choice of required characteristics;

- carrying out numerical calculations of characteristics and optimal parameters for a headframe;

- result visualization (construction of intermediate and final structures);

- formation of the design drawing of the MPH headframe.

The package was created using AutoCAD in the AutoLISP programming language.

Figure 2 shows the process of applying the software package. As it can be seen from the figure, calculation of optimal parameters for a headframe and its construction is iterative. During calculation process, characteristics are refined, and parameters are recalculated depending on the obtained results.

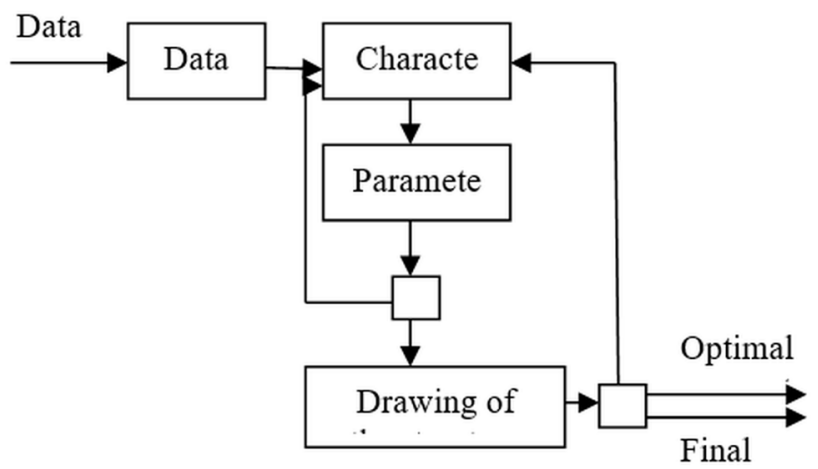

Fig. 2. Process of the software package application.

The software package consists of three large blocks of functions: to load and select data; numerically calculate parameters as per a built mathematical model; construct a structure on the step-by-step method, and form documentation for subsequent manufacture. The database contains files that reflect dimensions of conveyances, design characteristics of ropes, headframe pulleys, hoists, and other technical characteristics essential for calculations.

\section{Conclusion}

The headframe construction algorithm provides existence of restrictions on the calculated values of characteristics and parameters. The software package allows a user to alter values of a number of characteristics manually. Visualization of the process of the structure headframe step-by-step construction allows you to make a necessary choice of parameters (Fig. 3).

As a result of calculations, the obtained optimal parameters (including a list of elements) and the final design of the headframe are output, in accordance with the initial data. (Fig. 4).

A test experiment was conducted to construct a MPH headframe of cage hoist for the following data $H_{h f}=33 \div 34 \mathrm{~m}, l=21 \div 26 \mathrm{~m}, H=400 \div 600 \mathrm{~m}, D_{\text {shaft }}=8 \div 9 \mathrm{~m}, t_{\mathrm{mm}}=1 \mathrm{~m}$. 
As can be seen from figure 4, at the final stage, a headframe drawing with a final list of elements was obtained.

\section{References}

1. D. W. Butler, A. C. Schneyderberg, Mining Congress Journal, 7(1), 15 (1982)

2. F. A. Edwards, Society for Mining, Metallurgy, and Exploration, 2 (1992)

3. J. I. Rojas-Sola, J. M. Montalvo-Gil, M. Castro-Garcia, Dyna, 181, 118 (2013)

4. J. I. Rojas-Sola, I. Palomares-Muñoz, Dyna, 6, 602 (2015)

5. L. Kelly, Northern Ontario business, 34(3), 31 (2014)

6. E. U. Reuther, Einführung in den Bergbau, 1(34) (1992)

7. E. U. Reuther, Erster Band, 12, 37 (2010)

8. S. Kostyuk, A. Gegreen, V. Meljnik, M. Lupeey, E3S Web Conf., 21, 01035 (2017)

9. E. G. Kassikhina, Gornyi zhurnal 8, 56 (2017) 